\title{
Amyloid $\beta$ Modification: A Key to the Sporadic Alzheimer's Disease?
}

\author{
Evgeny P. Barykin, Vladimir A. Mitkevich *, Sergey A. Kozin and Alexander A. Makarov \\ Engelhardt Institute of Molecular Biology, Russian Academy of Sciences, Moscow, Russia
}

Keywords: beta amyloid, post-translational Modifications (PTM), proteostasis, Sporadic Alzheimer's disease, proteinopathies, Aging

\section{OPEN ACCESS}

Edited by:

Alexey Moskalev

Institute of Biology of Komi Scientific

Center of Ural Division of RAS, Russia

Reviewed by:

Elena Marcello,

Università degli Studi di Milano, Italy

James C. Vickers,

University of Tasmania, Australia

*Correspondence:

Vladimir A. Mitkevich

mitkevich@gmail.com

Specialty section:

This article was submitted to

Genetics of Aging,

a section of the journal

Frontiers in Genetics

Received: 28 February 2017 Accepted: 27 April 2017

Published: 15 May 2017

Citation:

Barykin EP, Mitkevich VA, Kozin SA and Makarov AA (2017) Amyloid $\beta$ Modification: A Key to the Sporadic

Alzheimer's Disease?

Front. Genet. 8:58

doi: 10.3389/fgene.2017.00058
Last year marked 25 years of research into the amyloid hypothesis of Alzheimer's disease (AD) (Selkoe and Hardy, 2016). Over the last few years, studies on this subject have provided a number of insights into the pathology of the most widespread cognitive disorder of aging; however, a successful treatment strategy has yet to be developed. The amyloid hypothesis was on the edge of being discredited due to the indistinct correlation between $\beta$-amyloid $(\mathrm{A} \beta)$ deposition and neuronal loss (Holmes et al., 2008; Mullane and Williams, 2013). However, recent studies have defended the $\mathrm{A} \beta$ peptide as a causative factor in $\mathrm{AD}$ and have proved it to be necessary but not sufficient to explain the pathogenesis of the disease in full (Musiek and Holtzman, 2015). An updated hypothesis suggests that, $A \beta$ accumulation is an essential trigger that initiates a pathological cascade implicating tau protein, synuclein, and other aggregation-prone proteins. The questions still to be answered are: which events pull the trigger on the $\mathrm{A} \beta$ aggregation cascade and how exactly does destabilization of amyloid proteostasis promote the downstream tau pathology. The answer to the first question is clear and transparent in familial $A D(f A D)$ as it is induced by genetic aberrations. However, it remains a mystery in so-called sporadic AD (sAD), which accounts for more than $90 \%$ of the disease cases. Currently, sporadic $\mathrm{AD}$ is a major subject of study with the primary focus being, to make it "less sporadic" by finding a genetic or aging-related basis for the disease.

A possible insight into the problem of $\mathrm{sAD}$ was found within the amyloid plaques. An analysis of plaque composition has shown that aggregated $\beta$-amyloid peptides are modified in different ways, primarily by isomerization and truncation of $A \beta$ (Roher et al., 1993). Subsequent in vitro and in vivo studies revealed that a plethora of modifications exhibit pathogenic features; these include: increased aggregation, neurotoxicity, amyloidogenicity, and an ability to suppress long-term potentiation in the hippocampus (Shimizu et al., 2002; Kumar, 2011; Al-Hilaly et al., 2013; Kozin S. et al., 2013; Mitkevich et al., 2013; Barykin et al., 2016).

Hence, we propose a model in which, aberrant post-translational modification (PTM) of the amyloid $\beta$ peptide increases amyloid neurotoxicity and facilitates its aggregation thus initiating or promoting progression of sAD.

\section{A $\beta$ PEPTIDE: FROM INTACT TO MODIFIED}

Amyloid $\beta$ modification is a complex process that occurs both enzymatically and nonenzymatically. Many proteins are already shown to interact with $A \beta$ leading to alteration of its structure or repair of pathogenic modifications. However, for many modified $A \beta$ species, purified from AD brain tissue, the source of origin remains unknown (Kummer and Heneka, 2014).

Prior to discussing the role of modified $A \beta$ in $\mathrm{sAD}$, we will first focus on the life cycle of the $A \beta$ molecule from its formation to its degradation or aggregation; taking into consideration, all modifications along the way. Beta-amyloid is produced via proteolytic cleavage of APP protein by beta-secretase (BACE) and gamma-secretase (Huang and Mucke, 2012); this is termed the amyloidogenic pathway. The non-amyloidogenic pathway is mediated by alpha-secretase (ADAM10). It is important to mention that cleavage by gamma-secretase is imprecise and results 
in production of an $\mathrm{A} \beta$ peptide ranging from 37 to 43 amino acids in length; notably the 42 residue species is considered to be the most pathogenic (Haass and Selkoe, 2007). Production of A $\beta$ may occur at three different sites: on the plasma membrane, in the ER/Golgi or in endocytic vesicles. This decision helps determine its fate and defines the set of possible modifications that can be made to the peptide, as different $A \beta$-modifying enzymes are assigned to specific cellular compartments (Hartmann et al., 1997; Thinakaran and Koo, 2008). In Figure 1 below, we present a putative scheme for the amyloid peptide modification process inside and outside of the cell and both in solution and as aggregates (Figure 1). Some of the modifications present are enzymatic, some are triggered by low-molecular compounds such as peroxynitrite or 4-hydroxynonenal (HNE), and two of them are spontaneous, namely racemization and isomerization. Formation of N-truncated amyloid has not been well studied, however it is possible that it originates from proteolytic cleavage by aminopeptidase A (ENPEP), meprin or BACE or alternatively via non-enzymatic hydrolysis of peptide bonds (Kummer and Heneka, 2014). A huge body of evidence supports the pathogenic role of individual $A \beta$ modifications; however, no research has been done to investigate the orchestrated action of different modifications on a single molecule of amyloid peptide. Additive or synergistic effects of such modifications may potentially increase the pathogenic properties of $\mathrm{A} \beta$ peptide far above the level of the widely studied intact $A \beta$. These modifications can promote accumulation of amyloid and plaque formation as they hamper its clearance and increase aggregation (Kumar, 2011; Kozin S. A. et al., 2013). Another blind spot in the studies of A $\beta$ PTM is its connection with tau pathology. Tau hyperphosphorylation (HP) is presumably induced by $\mathrm{A} \beta$, leading to systemic brain pathology (Oddo et al., 2006) and this transition might be caused by modified $\mathrm{A} \beta$ peptides. However, the association of HP-tau and A $\beta$ modifications was only studied and observed for pyroglutamylated amyloid peptide (Mandler et al., 2014). We propose that studies of the relationship between A $\beta$ PTM and tau pathology may contribute substantially to the understanding of $\mathrm{AD}$ development.

\section{AGING INTERFERES WITH A $\beta$ MODIFICATION}

The principal fact that drew our attention to amyloid PTMs as a presumable cause of $\mathrm{sAD}$, is that the PTM process is disrupted with aging. It was shown both directly in studies where the accumulation of modified proteins was measured (Levine and Stadtman, 2001), and indirectly as we know that proteostasis itself is disturbed in the aged body (Dubnikov and Cohen, 2015; Labbadia and Morimoto, 2015). It is known that reactive oxygen species (ROS) production and neutralization is destabilized in the aged body due to elevation of NOX activity (Dasuri et al., 2013) and an increase in mitochondrial respiratory chain leakage that is accompanied by an accumulation of mutations in mitochondrial DNA (Bratic and Larsson, 2013). HNE is a product of lipid peroxidation and its production increases with aging as a side effect of chronic oxidative stress (Castro et al., 2016). It has also been shown that nitric oxide synthase is upregulated in $\mathrm{AD}$; however, it is not clear whether it is a normal part of the aging process or a pathological event (DomekŁopacińska and Strosznajder, 2010). Meanwhile, isomerized and deaminated proteins have a tendency to accumulate naturally in an aging organism, and in carboxyl methyltransferase-deficient mice damaged proteins have also been shown to accumulate in the brain (Kim et al., 1997; Clarke, 2003). The phosphorylation process is regulated by balancing kinase and phosphatase activity and is also disrupted with aging (Magnoni et al., 1991; Rajagopal et al., 2016; Thomas and Haberman, 2016). Citrullination is another modification that is known to increase in aged body (Osaki and Hiramatsu, 2016). The important point is that modifications can create pathogenic networks with a positive feedback. It was shown that ROS-induce dityrosine crosslinking of $A \beta$ results in formation of stable and poorly degradable oligomers (Al-Hilaly et al., 2013). A $\beta$ increases ROS production (Butterfield and Swomley, 2012), which then promotes further inhibition of the amyloid clearance system and may result in a positive feedback-driven cascade of accumulation; such a cascade has already been shown for the $A \beta$ and HNE interaction (Ellis et al., 2010). Taken together, all of these findings make it probable that disturbance of $A \beta$ modification processes with age leads to the rise of different pathogenic processes including $\mathrm{AD}$.

\section{HEREDITARY VARIANCE OF AMYLOID PTMS}

Since we propose an aging-related disturbance in the $\mathrm{A} \beta$ modification process as a cause of $\mathrm{AD}$, one may ask whether every aging individual is destined to suffer from $A \beta$ accumulation, $A D$, and a resulting steady cognitive decline with age. This does not happen and $\mathrm{AD}$ obviously requires additional triggers besides senescence-related pathogenic modification of $\mathrm{A} \beta$ peptides. These triggers are widely discussed and a plethora of work has been conducted to identify $\mathrm{AD}$ risk factors. The risk factors identified include: smoking, sleep deprivation, brain trauma, diabetes, bacterial infections, viral infections, and gut microbiota alteration (Itzhaki et al., 1997; Miklossy, 2008; Kang et al., 2009; Naseer et al., 2014; Reitz and Mayeux, 2014). The most studied trigger of $\mathrm{AD}$ is genetic background. According to estimations, based on human pedigree analysis, up to $80 \%$ of all Alzheimer's cases are hereditary (Bergem, 1994). The first genes that were identified as genes in which mutations lead to fAD were: APP, BACE, and gamma-secretase genes, called PSEN1 and PSEN2. They are responsible for most cases of familial AD and can dramatically increase overall $A \beta$ production or shift the production ratio in favor of $A \beta$ 1-42 (Bertram et al., 2010). Increased $A \beta$ burden results in early amyloid accumulation and this in turn leads to an early-onset development of brain pathology (Huang and Mucke, 2012). However, fAD only accounts for about $1 \%$ of registered $\mathrm{AD}$ cases and late-onset $\mathrm{AD}$ (LOAD) or $\mathrm{sAD}$ is more or less beyond prediction (Campion et al., 1999; Bertram et al., 2010). In sAD, ApoE gene variants were associated with an increased risk of disease and could account for up to $20 \%$ of LOAD cases (Ertekin-Taner, 2010). However, to date the efforts to identify other sAD-modifying genes with a comparable magnitude of influence have been 


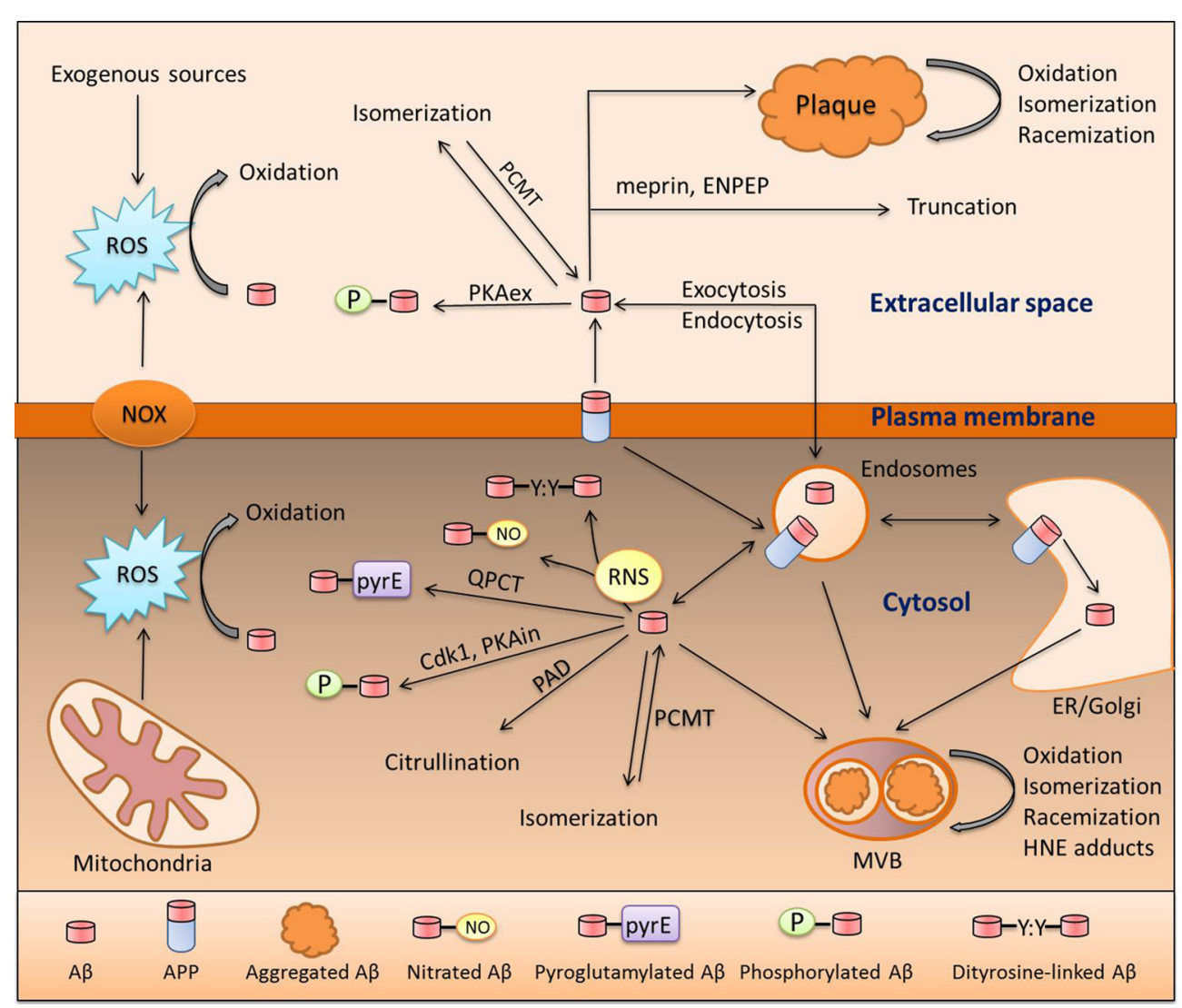

FIGURE 1 | Pathways of A $\boldsymbol{\beta}$ modification. $A \beta$ is a product of amyloid precursor protein (APP) cleavage at the plasma membrane or inside the cell in the endosomal compartment or ER/Golgi. These two pools exchange $A \beta$ via endo- and exocytosis. $A \beta$ in both of these pools can undergo oxidation due to interaction with reactive oxygen species (ROS) produced by NADPH-oxidase (NOX), the mitochondrial respiratory chain, or exogenous sources. Reactive nitrogen species (RNS) produced by nitric oxide synthase (NOS) isoforms also interact with $A \beta$ which, results in nitration of the Tyr10 residue or formation of covalently linked dimers of $A \beta$. Extracellular $A \beta$ is phosphorylated by extracellular protein kinase $A$ (PKAex) and intracellular A $\beta$ is subjected to phosphorylation by both intracellular PKA (PKAin) and cdc2 kinase (Cdk1). An exclusive modification of intracellular $A \beta$ is citrullination by peptidyl arginyl deiminase (PAD). Aspartic residues of $A \beta$ are prone to spontaneous isomerization or racemization, and this isomerization can be reversed by protein carboxyl methyltransferase 1 (PCMT1). In amyloid deposits (plaques or multivesicular bodies [MVB]), A $\beta$ undergoes oxidative damage which leads to the formation of adducts with 4-hydroxynonenal (HNE); a product of lipid peroxidation. Aminopeptidase A (ENPEP) and meprin can truncate A . Lastly, amyloid beta can be pyroglutamylated at the E3 and E11 sites by glutaminyl-peptide cyclotransferase (QPCT).

unsuccessful and we suggest that future work should focus on the genetics of $\mathrm{A} \beta$-modifying enzymes. Currently an association between genetic variants of $\mathrm{A} \beta$-modifying enzymes and $\mathrm{AD}$ is only shown for NOS2 (Akomolafe et al., 2006) and QPCT (Saykin et al., 2010), however for the latter the association does not have genome-wide significance. It is very possible that the lack of such associations is due to the nature of the tool that was used in prior studies to identify disease-modifying genes. The primary tool for such investigations is genome-wide association studies (GWAS), which have brought many gene-disease associations to our attention over the years (Singleton and Hardy, 2016). However, GWAS usually lacks full-genome coverage and fails to detect statistically significant associations with small effects (Naj et al., 2017). GWAS findings are dependent on a chosen cohort and many candidate genes are often thrown away. GWAS associations do not permit an inference of causation (Naj et al., 2017), so the role of individual genetic studies based on additional data is not diminished. Most enzymes featured in
Figure 1 are already associated with other genetic pathologies, including neurological diseases; ENPEP is associated with Koch Hypertension (Kato et al., 2011); QPCT is associated with schizophrenia and frontotemporal dementia (Zhang et al., 2016); and PCMT1 with premature ovarian failure (Pyun et al., 2009). Variants of these may likewise be important for the development of AD. Such guidance may facilitate further genetic studies taking into consideration the potential synergy between the impairment of different modifications.

$\mathrm{A} \beta$ modifications and genetic alterations is a vast, yet poorly studied field with the potential to contribute substantially to the understanding of $\mathrm{AD}$ pathogenesis. The modification process results in the formation of pathogenic $A \beta$ species, the level of which may increase with age and due to hereditary factors. To summarize, we hypothesize that modification of $\mathrm{A} \beta$ is a major contributor to SAD and targeting of the modified peptides or modification enzymes could serve as a novel therapeutic mechanism or provide a new means of diagnosis. 


\section{AUTHOR CONTRIBUTIONS}

All authors listed, have made substantial, direct and intellectual contribution to the work, and approved it for publication.

\section{REFERENCES}

Akomolafe, A., Lunetta, K., Erlich, P., Cupples, L., Baldwin, C., Huyck, M., et al. (2006). Genetic association between endothelial nitric oxide synthase and Alzheimer disease. Clin. Genet. 70, 49-56. doi: 10.1111/j.1399-0004.2006.00638.x

Al-Hilaly, Y. K., Williams, T. L., Stewart-Parker, M., Ford, L., Skaria, E., Cole, M., et al. (2013). A central role for dityrosine crosslinking of Amyloid- $\beta$ in Alzheimer's disease. Acta Neuropathol. Commun. 1:83. doi: 10.1186/2051-5960-1-83

Barykin, E. P., Petrushanko, I. Y., Burnysheva, K. M., Makarov, A. A., and Mitkevich, V. A. (2016). [Isomerization of Asp7 increases the toxic effects of amyloid beta and its phosphorylated form in SH-SY5Y neuroblastoma cells]. Mol. Biol. Mosk. 50, 863-869. doi: 10.7868/S0026898416050037

Bergem, A. L. M. (1994). Heredity in dementia of the Alzheimer type. Clin. Genet. 46, 144-149. doi: 10.1111/j.1399-0004.1994.tb04216.x

Bertram, L., Lill, C. M., and Tanzi, R. E. (2010). The Genetics of Alzheimer Disease: back to the future. Neuron 68, 270-281. doi: 10.1016/j.neuron.2010. 10.013

Bratic, A., and Larsson, N.-G. (2013). The role of mitochondria in aging. J. Clin. Invest. 123, 951-957. doi: 10.1172/JCI64125

Butterfield, D. A., and Swomley, A. M. (2012). Amyloid $\beta$-Peptide (1-42)-Induced Oxidative Stress in Alzheimer Disease: importance in Disease Pathogenesis and Progression. Antioxid. Redox Signal. 19, 823-835. doi: 10.1089/ars.2012.5027

Campion, D., Dumanchin, C., Hannequin, D., Dubois, B., Belliard, S., Puel, M., et al. (1999). Early-onset autosomal dominant Alzheimer disease: prevalence, genetic heterogeneity, and mutation spectrum. Am. J. Hum. Genet. 65, 664-670. doi: $10.1086 / 302553$

Castro, J. P., Jung, T., Grune, T., and Siems, W. (2016). 4-Hydroxynonenal (HNE) modified proteins in metabolic diseases. Free Radic. Biol. Med. doi: 10.1016/j.freeradbiomed.2016.10.497. [Epub ahead of print].

Clarke, S. (2003). Aging as war between chemical and biochemical processes: protein methylation and the recognition of age-damaged proteins for repair. Ageing Res. Rev. 2, 263-285. doi: 10.1016/S.1568-1637(03)00011-4

Dasuri, K., Zhang, L., and Keller, J. N. (2013). Oxidative stress, neurodegeneration, and the balance of protein degradation and protein synthesis. Free Radic. Biol. Med. 62, 170-185. doi: 10.1016/j.freeradbiomed.2012.09.016

Domek-Łopacińska, K. U., and Strosznajder, J. B. (2010). Cyclic GMP and Nitric Oxide Synthase in Aging and Alzheimer's Disease. Mol. Neurobiol. 41, 129-137. doi: 10.1007/s12035-010-8104-x

Dubnikov, T., and Cohen, E. (2015). Proteostasis collapse, inter-tissue communication, and the regulation of aging at the organismal level. Front. Genet. 6:80. doi: 10.3389/fgene.2015.00080

Ellis, G., Fang, E., Maheshwari, M., Roltsch, E., Holcomb, L., Zimmer, D., et al. (2010). Lipid oxidation and modification of amyloid- $\beta(\mathrm{A} \beta)$ in vitro and in vivo. J. Alzheimers Dis. 22, 593-607. doi: 10.3233/JAD-2010-100960

Ertekin-Taner, N. (2010). Genetics of Alzheimer disease in the pre- and postGWAS era. Alzheimers Res. Ther. 2:3. doi: 10.1186/alzrt26

Haass, C., and Selkoe, D. J. (2007). Soluble protein oligomers in neurodegeneration: lessons from the Alzheimer's amyloid beta-peptide. Nat. Rev. Mol. Cell Biol. 8, 101-112. doi: 10.1038/nrm2101

Hartmann, T., Bieger, S. C., Brühl, B., Tienari, P. J., Ida, N., Allsop, D., et al. (1997). Distinct sites of intracellular production for Alzheimer's disease A $\beta 40 / 42$ amyloid peptides. Nat. Med. 3, 1016-1020. doi: 10.1038/nm0997-1016

Holmes, C., Boche, D., Wilkinson, D., Yadegarfar, G., Hopkins, V., Bayer, A., et al. (2008). Long-term effects of $A \beta 42$ immunisation in Alzheimer's disease: followup of a randomised, placebo-controlled phase I trial. Lancet 372, 216-223. doi: 10.1016/S0140-6736(08)61075-2

Huang, Y., and Mucke, L. (2012). Alzheimer Mechanisms and Therapeutic Strategies. Cell 148, 1204-1222. doi: 10.1016/j.cell,0.2012.02.040

\section{FUNDING}

The study was funded by the Russian Science Foundation (grant \#14-24-00100).

Itzhaki, R. F., Lin, W.-R., Shang, D., Wilcock, G. K., Faragher, B., and Jamieson, G. A. (1997). Herpes simplex virus type 1 in brain and risk of Alzheimer's disease. Lancet 349, 241-244. doi: 10.1016/S0140-6736(96)10149-5

Kang, J.-E., Lim, M. M., Bateman, R. J., Lee, J. J., Smyth, L. P., Cirrito, J. R., et al. (2009). Amyloid- $\beta$ dynamics are regulated by orexin and the sleep-wake cycle. Science 326, 1005-1007. doi: 10.1126/science.1180962

Kato, N., Takeuchi, F., Tabara, Y., Kelly, T. N., Go, M. J., Sim, X., et al. (2011). Meta-analysis of genome-wide association studies identifies common variants associated with blood pressure variation in east Asians. Nat. Genet. 43, 531-538. doi: 10.1038/ng.834

Kim, E., Lowenson, J. D., MacLaren, D. C., Clarke, S., and Young, S. G. (1997). Deficiency of a protein-repair enzyme results in the accumulation of altered proteins, retardation of growth, and fatal seizures in mice. Proc. Natl. Acad. Sci. U.S.A. 94, 6132-6137. doi: 10.1073/pnas.94.12.6132

Kozin, S. A., Cheglakov, I. B., Ovsepyan, A. A., Telegin, G. B., Tsvetkov, P. O., Lisitsa, A. V., et al. (2013). Peripherally Applied Synthetic Peptide isoAsp7A $\beta$ (1-42) Triggers Cerebral $\beta$-Amyloidosis. Neurotox. Res. 24, 370-376. doi: 10.1007/s12640-013-9399-y

Kozin, S., Cheglakov, I., Ovsepyan, A., Telegin, G., Tsvetkov, P., Lisitsa, A., et al. (2013). Amyloidogenic properties of isoAsp7-containing beta-amyloid peptide. Alzheimers Dement. J. Alzheimers Assoc. 9:P857. doi: 10.1016/j.jalz.2013. 08.176

Kumar, S. (2011). Phosphorylation of amyloid beta $(A \beta)$ peptides - A trigger for formation of toxic aggregates in Alzheimer's disease. Aging 3, 803-812. doi: 10.18632/aging.100362

Kummer, M. P., and Heneka, M. T. (2014). Truncated and modified amyloid-beta species. Alzheimers Res. Ther. 6:28. doi: 10.1186/alzrt258

Labbadia, J. and Morimoto, R. I. (2015). The Biology of Proteostasis in Aging and Disease. Annu. Rev. Biochem. 84, 435-464. doi: 10.1146/annurev-biochem-060614-033955

Levine, R. L., and Stadtman, E. R. (2001). Oxidative modification of proteins during aging. Exp. Gerontol. 36, 1495-1502. doi: 10.1016/S0531-5565(01)00135-8

Magnoni, M. S., Govoni, S., Battaini, F., and Trabucchi, M. (1991). The aging brain: protein phosphorylation as a target of changes in neuronal function. Life Sci. 48, 373-385. doi: 10.1016/0024-3205(91)90492-T

Mandler, M., Walker, L., Santic, R., Hanson, P., Upadhaya, A. R., Colloby, S. J., et al. (2014). Pyroglutamylated amyloid- $\beta$ is associated with hyperphosphorylated tau and severity of Alzheimer's disease. Acta Neuropathol. (Berl.) 128, 67-79. doi: 10.1007/s00401-014-1296-9

Miklossy, J. (2008). Chronic Inflammation and Amyloidogenesis in Alzheimer's Disease - Role of Spirochetes. J. Alzheimers Dis. 13, 381-391. doi: 10.3233/JAD-2008-13404

Mitkevich, V. A., Petrushanko, I. Y., Yegorov, Y. E., Simonenko, O. V., Vishnyakova, K. S., Kulikova, A. A., et al. (2013). Isomerization of Asp7 leads to increased toxic effect of amyloid-beta42 on human neuronal cells. Cell Death Dis 4:e939. doi: 10.1038/cddis.2013.492

Mullane, K., and Williams, M. (2013). Alzheimer's therapeutics: continued clinical failures question the validity of the amyloid hypothesis-but what lies beyond? Biochem. Pharmacol. 85, 289-305. doi: 10.1016/j.bcp.2012.11.014

Musiek, E. S., and Holtzman, D. M. (2015). Three dimensions of the amyloid hypothesis: time, space, and “wingmen." Nat. Neurosci. 18, 800-806. doi: $10.1038 / \mathrm{nn} .4018$

Naj, A. C., Schellenberg, G. D., and for the Alzheimer's Disease Genetics Consortium (2017). Genomic variants, genes, and pathways of Alzheimer's disease: an overview. Am. J. Med. Genet. B Neuropsychiatr. Genet. 174, 5-26. doi: 10.1002/ajmg.b.32499

Naseer, M. I., Bibi, F., Alqahtani, M. H., Chaudhary, A. G., Azhar, E. I., Kamal, M. A., et al. (2014). Role of gut microbiota in obesity, Type 2 diabetes and Alzheimer's Disease. CNS Neurol. Disord. Drug Targets 13, 305-311. doi: $10.2174 / 18715273113126660147$ 
Oddo, S., Caccamo, A., Tran, L., Lambert, M. P., Glabe, C. G., Klein, W. L., et al. (2006). Temporal Profile of Amyloid- $\beta$ (A $\beta$ ) Oligomerization in an in vivo Model of Alzheimer Disease A LINK BETWEEN A $\beta$ AND TAU PATHOLOGY. J. Biol. Chem. 281, 1599-1604. doi: 10.1074/jbc.M507892200

Osaki, D., and Hiramatsu, H. (2016). Citrullination and deamidation affect aggregation properties of amyloid $\beta$-proteins. Amyloid 23, 234-241. doi: 10.1080/13506129.2016.1240076

Pyun, J.-A., Kang, H., Lee, S. K., Kim, M., and Kwack, K. (2009). Association between polymorphisms in the protein L-isoaspartate (D-aspartate) Omethyltransferase gene and premature ovarian failure. Fertil. Steril. 91, 1362-1365. doi: 10.1016/j.fertnstert.2008.03.078

Rajagopal, S., Deb, I., Poddar, R., and Paul, S. (2016). Aging is associated with dimerization and inactivation of the brain-enriched tyrosine phosphatase STEP. Neurobiol. Aging 41, 25-38. doi: 10.1016/j.neurobiolaging.2016.02.004

Reitz, C., and Mayeux, R. (2014). Alzheimer disease: epidemiology, diagnostic criteria, risk factors and biomarkers. Biochem. Pharmacol. 88, 640-651. doi: 10.1016/j.bcp.2013.12.024

Roher, A. E., Lowenson, J. D., Clarke, S., Wolkow, C., Wang, R., Cotter, R. J., et al. (1993). Structural alterations in the peptide backbone of beta-amyloid core protein may account for its deposition and stability in Alzheimer's disease. J. Biol. Chem. 268, 3072-3083.

Saykin, A. J., Shen, L., Foroud, T. M., Potkin, S. G., Swaminathan, S., Kim, S., et al. (2010). Alzheimer's Disease Neuroimaging Initiative biomarkers as quantitative phenotypes: genetics core aims, progress, and plans. Alzheimers Dement. 6, 265-273. doi: 10.1016/j.jalz.2010.03.013

Selkoe, D. J., and Hardy, J. (2016). The amyloid hypothesis of Alzheimer's disease at 25 years. EMBO Mol. Med. 8, 595-608. doi: 10.15252/emmm.201606210
Shimizu, T., Fukuda, H., Murayama, S., Izumiyama, N., and Shirasawa, T. (2002). Isoaspartate formation at position 23 of amyloid beta peptide enhanced fibril formation and deposited onto senile plaques and vascular amyloids in Alzheimer's disease. J. Neurosci. Res. 70, 451-461. doi: 10.1002/jnr. 10350

Singleton, A., and Hardy, J. (2016). The evolution of genetics: Alzheimer's and Parkinson's Diseases. Neuron 90, 1154-1163. doi: 10.1016/j.neuron.2016.05.040

Thinakaran, G., and Koo, E. H. (2008). Amyloid precursor protein trafficking, processing, and function. J. Biol. Chem. 283, 29615-29619. doi: $10.1074 /$ jbc.R800019200

Thomas, A., and Haberman, A. (2016). Phosphorylation of Neuronal Proteins in Drosophila melanogaster Changes With Age. FASEB J. 30, 1080.3-1080.3.

Zhang, Q.-Q., Jiang, T., Gu, L.-Z., Zhu, X.-C., Zhao, H.-D., Gao, Q., et al. (2016). Common Polymorphisms Within QPCT Gene Are Associated with the Susceptibility of Schizophrenia in a Han Chinese Population. Mol. Neurobiol. 53, 6362-6366. doi: 10.1007/s12035-015-9541-3

Conflict of Interest Statement: The authors declare that the research was conducted in the absence of any commercial or financial relationships that could be construed as a potential conflict of interest.

Copyright () 2017 Barykin, Mitkevich, Kozin and Makarov. This is an open-access article distributed under the terms of the Creative Commons Attribution License (CC $B Y$ ). The use, distribution or reproduction in other forums is permitted, provided the original author(s) or licensor are credited and that the original publication in this journal is cited, in accordance with accepted academic practice. No use, distribution or reproduction is permitted which does not comply with these terms. 